\title{
EFFECT OF (SIM) SELF INSTRUCTIONAL MODULE REGARDING HOMECARE MANAGEMENT ON KNOWLEDGE AMONG PATIENTS WITH PERMANENT PACEMAKER \\ *Mr. R. Velmurugan
}

\begin{abstract}
:
With a view to assess the effectiveness of self instructional module on home care management of patients with permanent pacemaker, a quasi experimental study with a quantitative approach was undertaken on 58 patients with permanent pacemaker. Purposive sampling technique was used in selecting permanent pacemaker patients. Prior to implementation of self instructional module the patients with permanent pacemaker had poor knowledge, whereas after implementation of self instructional module the patient with permanent pacemaker knowledge significantly improved with the difference of mean percentage revealing effectiveness of self instructional module. It was also found that the patients with permanent pacemaker were not aware of the importance of home caremanagement.
\end{abstract}

Key words: Self instructional module, Poor Knowledge, Permanent Pacemaker, Home care Management.

\section{Introduction:}

The pacemaker is an electronic biomedical device that can regulate the human heartbeat, when it's natural regulating mechanisms breakdown. It is a small box surgically implanted in the chest cavity and has electrodes that are in direct contact with the heart. (Banbury.C.2004) An artificial pacemaker contains a battery and circuit, which produces electrical pulses of short duration capable of stimulating the heart. There are commonly two types, temporary pacemakers and permanent pacemakers ${ }^{1}$.

Gabriel, M.D reported that approximately $1,20,000$ new permanent pacemakers are implanted and forty thousand patients are replaced annually, and about 9,00000 permanent pacemakers are implanted in worldwide ${ }^{2}$. The complications associated with permanent pacemakerrelate to their presence within the body, and improper functioning. The complications are local infections, hematoma, hemothorax, cardiac tamponade ${ }^{3}$. The most common complication of permanent pacemaker is infection at the incision site ${ }^{4}$.

The main objective of home care management is to help the patients with permanent pacemaker for understanding the complication $^{5}$. Self instructional module is a kind of booklet which helps for permanent pacemaker patients to prevent the complications.

\section{Objectives:}

The study attempted

i) To assess the effectiveness of SIM (self instructional module) on knowledge of home care management among patients with permanentpacemaker. 
ii) To find out the association between the knowledge scores of patients regarding home care management of permanent pacemaker with selected demographic variables

\section{Hypotheses:}

Ho $_{1}$ : There is no significant difference between pre test and post test knowledge score of patients with permanent pacemaker regarding home care management.

Ho$_{2}$ : There is no significant association between posttest knowledge score of patients with permanent pacemaker regarding home caremanagement

\section{Methodology:}

A quasi experimental with pre and post test without control group and quantitative approach was selected to carry out the study. The study population comprised of all patients with permanent pacemaker attending cardiology OPD in a selected hospital.Thesamplesizeforthestudywas

58 patients with permanent pacemaker.
Purposive sampling technique was used for selecting the sample. The tools used for the study were (i) closed ended questionnaire to assess the knowledge regarding home care management of patients with permanent pacemaker. Part A. Demographic variables. Part B. Home care management of patients with permanent pacemaker. Part C. Self instructional module regarding home care management.

\section{Results:}

The frequency and percentage wise distribution of demographic variables of patients with permanent pacemaker revealed the highest percentage (37.93\%) of the patients with permanent pacemaker were in the age group of $41-50 \mathrm{yrs},(41.38 \%)$ had high school education, (29.31\%) had own business and were working in private companies, (62.07\%) monthly income was of above Rs. 9000, (63.79\%) were living in urban area and $(37.93 \%)$ were received information from other patients. Higher percentage of them were males $(58.62 \%)$

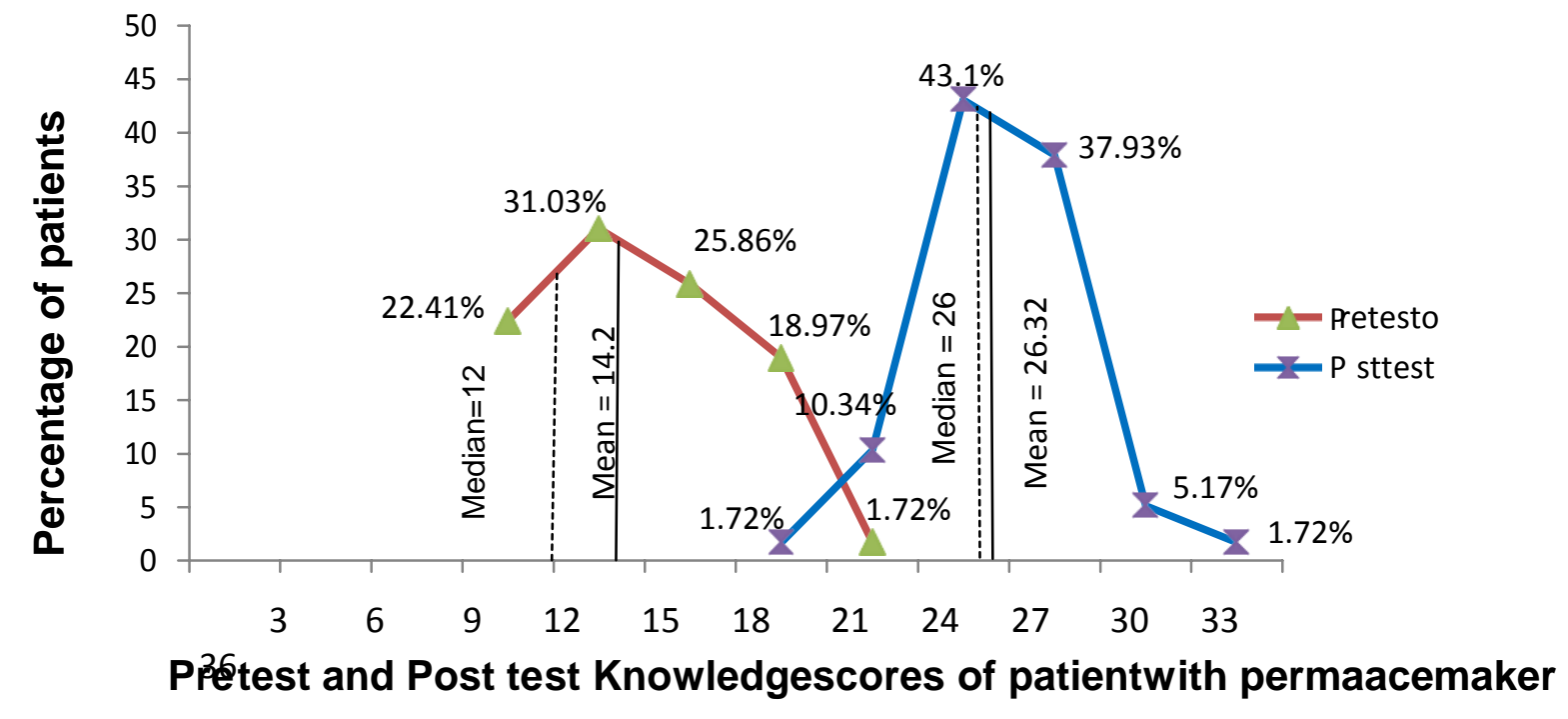


The overall pre test mean score was 37.6 percent (14.2 \pm 3.28$)$ whereas in post testthemean score was 69.26 percent $(26.32 \pm 2.44)$ revealing effectiveness of Self Instruction Module regarding knowledge on home care management permanent pacemaker.

Paired $\mathrm{t}$ test was used to assess the significant difference between pre and post test knowledge scores regarding homecare management of permanent pacemaker. Thefinding shows that there was a significant difference between pre test and post test at the level of $\mathrm{p}<0.001$.

Chi-square test was used to find out the association between the posttest knowledge scores and demographic variables of the patients with permanent pacemaker. No significant association was found between posttest knowledge scores patients with permanent pacemaker when compared to

Age, Gender, Educational status, Occupation, Family monthly income, residential area and previous source of information regarding home care management.

\section{Discussion:}

The overall pre test mean score was $14.2 \pm 3.28$ which is 37.6 percent whereas, in post test the mean score was $26.32 \pm 2.44$ which is 69.26 percent revealing the Self Instructional Module was effective on variousareasof-Homecaremanagementof permanent pacemakerl. This finding is supported by Norlander. R (2003) who also reported that patients from experimental area had more knowledge of homecarecare management of permanent pacemaker than patients of control area $(p<0.05)$ and the knowledge is promoted significantly by education.

No significant association was found between knowledge scores of the patients with permanent pacemaker in posttest when compared with age, gender, educational status, occupation, family monthly income, residential area and previous source of information. It seems that the self instructional module was effective for all irrespective of their demographic characteristics.

\section{Conclusion:}

Educating the patients with permanent pacemaker is so important for understand and prevent their complication associated with permanent pacemaker.

\section{Reference:}

1. Banbury.C. An electronic devices for heart. British journal of nursing: 2004; 72(4) 321323.

2. Gabriel, M.D. Incidence and prevalence'sof cardiac surgeries. Health economics: 2005; 45(7)765-769.

3. Alpert. M. Epidemiology in cardio vascular disorder. Indian journal of nursing: 2008; 24(12)943-945.

4. Djordjevic.M.et al. Text book of surgery. $1^{\text {st }}$ edition. New Delhi: Tata Mc.Grow Hill publication: 2004:Pp-102-107.

5. Sridevipitta. A. Pacemaker related complications. Journal of heart: 1998; 67(12)112-114. 